\title{
Peritoneal dialysis associated peritonitis secondary to Mycobacterium fortuitum
}

\author{
Paula McKenzie MD, David Sotello MD, Kunal Parekh MD, \\ Kristen Fuhrmann PharmD, Richard Winn MD
}

\begin{abstract}
We report a 23-year-old woman with systemic lupus erythematous, lupus nephritis (class IV), and end-stage renal disease on peritoneal dialysis who presented with abdominal pain, nausea, vomiting, and diarrhea for one week. A previous admission for peritonitis occurred one month earlier, and peritoneal fluid culture at that time was negative. She was discharged on three weeks of intraperitoneal cefepime and vancomycin. On the current admission, due to recurrent symptoms approximately two weeks after her antibiotics were discontinued, peritoneal fluid cultures were positive for Mycobacterium fortuitum. The peritoneal catheter was removed, and trimethoprim- sulfamethoxazole and ciprofloxacin were initially recommended for six months. This was later changed to trimethoprim-sulfamethoxazole and amikacin based on new susceptibilities.

$M$. fortuitum is a rapidly growing mycobacterial species (RGM) widely distributed in nature; tap water is the major reservoir. It can produce a wide range of infections in humans, and outbreaks have been reported in hospitals from contaminated equipment. Immunosuppression and chronic lung disease have been described as predisposing factors for RGM infection. Peritoneal dialysis associated with M. fortuitum infection occurs very rarely; no guidelines exist for treatment recommendations.
\end{abstract}

Key words: peritonitis, peritoneal dialysis, Mycobacterium fortuitum

\section{Case Presenttion}

A 23-year-old woman with systemic lupus erythematous, lupus nephritis (class IV), hypertension with retinopathy, chronic anemia, and end-stage renal disease on peritoneal dialysis since October 2013 presented to the emergency department in January 2014 with abdominal pain, nausea, vomiting, and diarrhea for one week. She admitted that during a re-

Corresponding author: David Sotello MD

Contact Information: david.sotello@ttuhsc.edu.

DOI: 10.12746/swrccc2014.0208.105 cent road trip she had not strictly adhered to an aseptic technique during her peritoneal dialysis.

Vital signs revealed blood pressure 98/64 $\mathrm{mmHg}$, heart rate 122 beats/minute, respiration rate 27 breaths/minute, and temperature $100.9^{\circ} \mathrm{F}$. Her abdomen was tender in the lower quadrants bilaterally without rebound tenderness; a peritoneal dialysis catheter was in place with no erythema or drainage from the catheter site.

This patient had been on continuous ambulatory peritoneal dialysis (CAPD) with four exchanges 
per day of 2 liters of $1.5 \%$ dialysate. She had been admitted in December 2013 with similar symptoms; the peritoneal fluid studies during that admission are shown in Table 1. A CT scan of her abdomen performed then was negative for intra-abdominal abscess. She was discharged on intraperitoneal cefepime and vancomycin for three weeks. One week prior to admission in January 2014, the patient again began to experience abdominal pain, and fluid was collected from her peritoneal catheter for culture. She was readmitted and started on empiric treatment with intravenous meropenem and vancomycin for seven days. Peritoneal fluid studies are shown in Table 1; cultures grew out Mycobacterium fortuitum. The peritoneal catheter was removed, six months of antimicrobial therapy with trimethoprim- sulfamethoxazole (TMP-SMX) and ciprofloxacin was started, and she was started on hemodialysis. Treatment was modified based on susceptibility data to TMP-SMX and amikacin (Table 2). She has had no recurrent episodes of peritonitis on this treatment.

Table 1: Peritoneal fluid analysis

\begin{tabular}{|c|c|c|}
\hline Variable & Dec 2013 & Jan 2014 \\
\hline Color & Yellow & Yellow \\
\hline Clarity & Clear & Hazy \\
\hline $\begin{array}{l}\text { Red Blood Cells } \\
\left(\text { cells } / \mathrm{mm}^{3}\right)\end{array}$ & 10 & 585 \\
\hline $\begin{array}{l}\text { White Blood Cells } \\
\left(\text { cells } / \mathrm{mm}^{3}\right)\end{array}$ & 250 & 1232 \\
\hline Neutrophils (\%) & 61 & 64 \\
\hline Lymphocytes (\%) & 28 & 17 \\
\hline Monocytes (\%) & 11 & 10 \\
\hline Eosinophils (\%) & 0 & 5 \\
\hline Basophils (\%) & 0 & 0 \\
\hline Bands (\%) & 0 & 0 \\
\hline Macrophages (\%) & 0 & 4 \\
\hline $\begin{array}{l}\text { Gram stain and } \\
\text { aerobic/anaerobic } \\
\text { culture }\end{array}$ & No growth & $\begin{array}{l}<1+\text { Gram positive rods } \\
\text { resembling diptheroids }\end{array}$ \\
\hline
\end{tabular}


Table 2: Antimicrobial susceptibilities for $M$. fortuitum

\begin{tabular}{|l|l|l|}
\hline \multicolumn{1}{|c|}{ Antibiotic } & $\begin{array}{c}\text { Minimal inhibitory } \\
\text { concentration (mg/L) }\end{array}$ & Interpretation \\
\hline TMP-SMX & $1: 19$ & Susceptible \\
\hline Ciprofloxacin & 4 & Resistant \\
\hline Moxifloxacin & 2 & Intermediate \\
\hline Cefoxitin & 64 & Intermediate \\
\hline Amikacin & 2 & Susceptible \\
\hline Doxycycline & $>32$ & Resistant \\
\hline Clarithromycin & 8 & Resistant \\
\hline Linezolid & 8 & Susceptible \\
\hline Imipenem & 4 & Susceptible \\
\hline Minocycline & 8 & Resistant \\
\hline
\end{tabular}

\section{Discussion}

This patient had peritoneal dialysis associated peritonitis (PD-peritonitis) secondary to $\mathrm{Myco}$ bacterium fortuitum, which is a very uncommon etiologic agent for PD-peritonitis. M. fortuitum is a rapidly growing mycobacterium (RGM), which belongs to the nontuberculous mycobacteria (NTM), which has the unique characteristic of relatively rapid growth and culture positivity occurring in less than one week.

NTM are widely distributed in nature and have been isolated from water and soil. Tap water is the major reservoir. ${ }^{1}$ There are five groups that comprise several species of RGM; the most significant include $M$. fortuitum, M. abscessus, M. chelonae (Table 3).
These bacteria can produce a wide spectrum of diseases in immunocompetent and immunosuppressed patients and cause skin and soft tissue, catheter-related, bone, joint, lung, and central nervous system infections. Table 4 shows the most commonly found RGM by infection site. ${ }^{1,2,3}$ There have been outbreaks of infection with RGM in hospitals from contaminated hospital equipment and water sources. ${ }^{2}$ Predisposing factors for infection include an immunocompromised state (corticosteroids, HIV, malignancy) and chronic lung diseases (cystic fibrosis).

The diagnosis is made by isolation of the organism directly from tissue and body fluid samples in non-pulmonary diseases. For pulmonary disease the 
Table 3: Species belonging to the various groups of RGM

\begin{tabular}{|l|l|}
\hline \multicolumn{1}{|c|}{ Group } & \multicolumn{1}{|c|}{ Species } \\
\hline M. fortuitum group & $\begin{array}{l}\text { M. fortuitum, M. peregrinum, M. senegalense, M. } \\
\text { setense, M. conceptionense, third biovariant com- } \\
\text { plex (M. houstonense, M. brisbanense, M. mag- } \\
\text { eritense, M. septicum, M. porcinum, M. bonickei, } \\
\text { M. neworleansense) }\end{array}$ \\
\hline M. chelonae abscessus group & $\begin{array}{l}\text { M. chelonae, M. abscessus, M. immunogenum, M. } \\
\text { bolletii, M. massiliense }\end{array}$ \\
\hline M. smegmatis group & M. smegmatis, M. goodii, M. wolinsky \\
\hline M. mucogenicum group & M. mucogenicum, M. aubagnense, M. phocaicum \\
\hline Recently described fifth group & $\begin{array}{l}\text { M. flavescens, M. neoaurum, M. vaccae, M. phlei, } \\
\text { ticum, M. monacense, M. psychrotolerans }\end{array}$ \\
\hline
\end{tabular}

Table 4: RGM by their most common site of infection

\begin{tabular}{|l|l|}
\hline Skin and soft tissue & $\begin{array}{l}\text { M. fortuitum (localized), M. } \\
\text { abscessus (disseminated) }\end{array}$ \\
\hline Pulmonary & M. abscessus \\
\hline Healthcare-associated & M. fortuitum \\
\hline $\begin{array}{l}\text { Catheter related blood stream } \\
\text { infection }\end{array}$ & M. fortuitum \\
\hline Bone and joint & M. fortuitum \\
\hline Central nervous system & M. fortuitum \\
\hline Corneal & $\begin{array}{l}\text { M. fortuitum and } \text { M. chelonae } \\
\text { abscessus group }\end{array}$ \\
\hline Ear & M. abscessus \\
\hline
\end{tabular}


American Thoracic Society (ATS) and Infectious Disease Society of America (IDSA) criteria require clinical symptoms, an abnormal chest radiograph, three or more sputum samples, and exclusion of other disorders (Table 5). ${ }^{1,4}$ Specimens should be inoculated in both liquid and solid media; biochemical, chromatographic, and molecular techniques can be used for the identification of different species.
First line treatment for $M$. tuberculosis is not active against RGM. The usual duration of antibiotic therapy is four to six months but has been extended up to 12 months. M. fortuitum is usually sensitive to amikacin, ciprofloxacin, imipenem, and clarithromycin; resistance to cephalosporins, tetracyclines, and macrolides has been reported. There are no guidelines recommending specific treatment, but usually double or triple antibiotic coverage is used. ${ }^{5,6}$

Table 5: Summary of the ATS/IDSA diagnostic criteria for pulmonary nontuberculous mycobacterial infection

\begin{tabular}{|c|}
\hline \\
\hline $\begin{array}{l}\text { 1. Pulmonary symptoms, nodular or cavitary opacities on chest radiograph, or high- } \\
\text { resolution computed tomographic scan that shows multifocal bronchiectasis with } \\
\text { multiple small nodules }\end{array}$ \\
\hline and \\
\hline 2. Appropriate exclusion of other diagnoses \\
\hline Microbiologic \\
\hline $\begin{array}{l}\text { 1. Positive culture results from at least two separate expectorated sputum samples (If } \\
\text { the results from the initial sputum samples are nondiagnostic, consider repeat sputum } \\
\text { acid-fast bacillus [AFB] smears and cultures) }\end{array}$ \\
\hline or \\
\hline 2. Positive culture results from at least one bronchial wash or lavage \\
\hline or \\
\hline $\begin{array}{l}\text { 3. Transbronchial or other lung biopsy with mycobacterial histopathological features } \\
\text { (granulomatous inflammation or AFB) and positive culture for NTM or biopsy show- } \\
\text { ing mycobacterial histopathological features (granulomatous inflammation or AFB) } \\
\text { and one or more sputum or bronchial washings that are culture positive for NTM }\end{array}$ \\
\hline $\begin{array}{l}\text { 4. Expert consultation should be obtained when NTM are recovered that are either } \\
\text { infrequently encountered or that usually represent environmental contamination }\end{array}$ \\
\hline $\begin{array}{l}\text { 5. Patients who are suspected of having NTM lung disease but who do not meet the } \\
\text { diagnostic criteria should be followed until the diagnosis is firmly established or } \\
\text { excluded }\end{array}$ \\
\hline $\begin{array}{l}\text { 6. Making the diagnosis of NTM lung disease does not, per se, necessitate the institu- } \\
\text { tion of therapy, which is a decision based on potential risks and benefits of therapy for } \\
\text { individual patients }\end{array}$ \\
\hline
\end{tabular}


Author Affiliation: David Sotello is a resident in Internal Medicine at Texas Tech University Health Science Center in Lubbock, TX. Kunal Parekh is a fellow in nephrology at TTUHSC. Paula McKenzie and Richard Winn are faculty members in the Division of Infectious Disease at TTUHSC. Kristen Fuhrmann PharmD is a pharmacist at University Medical Center in Lubbock, TX.

Received: $07 / 10 / 2014$

Accepted: 09/21/2014

Reviewers: Vaqar Ahmed MD

Published electronically: 10/15/2014

Conflict of Interest Disclosures: none

\section{REFERENCES}

1. Set R, Shastri J. Laboratory aspects of clinically significant rapidly growing mycobacteria. Indian J Med Microbiol 2011 Oct-Dec; 29(4):343-52.

2. Hawkins C, Qi C, Warren J, Stosor V. Catheter related bloodstream infections caused by rapidly growing nontuberculous mycobacteria: a case series including rare species. Diagn Microbiol Infect Dis 2008 Jun; 61(2):187-91.

3. Lamy B, Marchandin H, Hamitouche K, Laurent F. Mycobacterium setense sp. nov., a Mycobacterium fortuitum-group organism isolated from a patient with soft tissue infection and osteitis. Int $J$ Syst Evol Microbiol 2008 Feb; 58(Pt 2): 486-90.

4. Griffith DE, Aksamit T, Brown-Elliott BA, et al; ATS Mycobacterial Diseases Subcommittee; American Thoracic Society; Infectious Disease Society of America. An official ATS/IDSA statement: diagnosis, treatment, and prevention of nontuberculous mycobacterial diseases. Am J Respir Crit Care Med 2007; 175(4): 367-416.

5. Eid AJ, Berbari EF, et al. Prosthetic joint infection due to rapidly growing mycobacteria: report of 8 cases and review of the literature. Clin Infect Dis 2007 Sep 15; 45(6): 687-94.

6. Jiang SH, Roberts DM, Dawson AH, Jardine M. Mycobacterium fortuitum as a cause of peritoneal dialysis associated peritonitis. BMC Nephrol 2012 Jun 8; 13:35.

7. Li PK, Szeto CC, Piraino B, et al. Peritoneal dialysis-related infections recommendations: 2010 update. Perit Dial Int 2010 Jul-Aug; 30(4): 393-423. 